\title{
Critérios de precificação dos dispositivos médicos no Brasil e sua relação com o aumento de gastos de saúde no país: uma estratégia de busca
}

\author{
Thais SEILER $^{(1)}$ \\ Jaqueline Vilela BULGARELI ${ }^{(1)}$ \\ ${ }^{(1)}$ Faculdade de Saúde Pública, Universidade de São Paulo - USP, São Paulo, SP, Brasil.
}

\section{Resumo}

Os dispositivos médicos são importantes instrumentos de saúde e estão presentes em nossa rotina. Estima-se que existam mais de 1,5 milhão de dispositivos médicos no mundo, divididos em mais de 12.000 tipos de grupos genéricos, ou seja, de usos iguais, tais como luvas, cateter venoso periférico, seringas, compressas, stents, entre outros. Dentro dos dispositivos médicos, temos a categoria de materiais que substituem partes do corpo, os chamados dispositivos médicos invasivos (DMI), também conhecidos no Brasil como OPME (Órteses, Próteses e Materiais Especiais), como válvula aórtica, próteses, marcapassos, entre outros. O consumo de materiais médicos cresceu 3,4\% no primeiro trimestre de 2018, frente ao período de 2017. As importações totais de materiais hospitalares, contabilizando de janeiro a março totalizaram o valor de US\$2,4 bilhões, com um crescimento de 5,9\% no mesmo período de 2017. No Brasil, o setor público e privado aumentou seu consumo devido à demanda por tecnologias para tratamento e diagnósticos frente às mudanças epidemiológicas,

Recebido: 28 jan 2019 Aceito: 10 fev 2019

Autor de correspondência: tataseiler@gmail.com

Conflito de interesses: Os autores declaram não haver nenhum interesse profissional ou pessoal que possa gerar conflito de interesses em relação a este manuscrito. sociais e demográficas. Embora o crescimento no mercado seja vasto e esteja em expansão, há muita divergência de informações disponível para consulta, seja sobre o padrão de descrição dos materiais, bem como evidências para os elevados preços desses produtos, em especial os da linha DMI. Um relatório realizado pela Agência Nacional de Vigilância Sanitária (Anvisa) apontou que boa parte dos dispositivos médicos tem mecanismos de desoneração tributária, que reduzem a carga tributária para alguns produtos ou estabelecimentos específicos como entidades filantrópicas, públicas e sem fins lucrativos. A indústria de materiais médicos tenta introduzir no mercado nacional e internacional seus produtos, com detalhes muita das vezes de forma não clara, pois são sistemas pouco regulamentados. A variação nos preços dos materiais hospitalares é impulsionada pela falta de transparência dos custos, bem como desalinhamento entre os agentes primários envolvidos na seleção de dispositivos (médicos e hospitais) e falta de transparência nos resultados de eficácia associados a esses dispositivos. Para a Aliança Brasileira de Indústria Inovadora em Saúde (ABIIS), a regulação de preços no mercado de dispositivos médicos não é produtiva, pois acreditam que a precificação de preços desestimularia os empreendedores, investidores e inventores no Brasil. Os produtos hospitalares têm um curto tempo de vida no mercado, logo se tornando ultrapassados, com isso, fazendo com que novos produtos que beneficiariam os pacientes não sejam lançados. A ABIIS 
defende que os preços abusivos devam ser combatidos através do Sistema Brasileiro de Defesa da Concorrência e recentemente reformados (Lei 12.529/2011), pela qual a Secretaria de Direito Econômico, do Ministério da Justiça (SDE/MJ) tem amplos poderes de fiscalização e o Conselho Administrativo de Defesa Econômica pode impor penas extremamente pesadas por práticas anticorrupção. Objetivo: compreender quais são os critérios de precificação dos dispositivos médicos no Brasil e de outros países e relacioná-los com o aumento de gastos de saúde no país. Método: a pesquisa é uma revisão da literatura do tipo metassíntese para identificar estudos relevantes à regulação de precificação de dispositivos médicos. Foi realizada pesquisa nas bases de dados: Biblioteca Virtual em Saúde (BVS) e Publicações Médicas (PubMed) utilizando a técnica de funil, combinando diversos descritores relacionados ao tema e utilizando as sintaxes necessárias para refinar a busca. A composição sintática realizada do tema parte da compreensão de quatro polos temáticos de interesse: (a) dispositivos médicos; (b) regulação de precificação de dispositivos médicos; e c) legislação de dispositivos médicos. A busca ocorreu, por meio da utilização conjunta dos Descritores em Ciências da Saúde (DeCS): Equipamentos e Provisões AND Legislação de Dispositivos Médicos AND Controle de Custos. A etapa de revisão e seleção buscou delimitar e organizar os dados por meio da seleção de artigos, avaliação dos títulos e leitura dos resumos. Nessa etapa, foram selecionados artigos cuja discussão era fundamentada em regulação de dispositivos médicos e precificação. Não houve restrição de idiomas e os critérios de inclusão para a elaboração do presente estudo foram: resumos disponíveis, disponibilidade do texto na íntegra. Não houve restrição de período de busca e não foram excluídos trabalhos na modalidade de pesquisa bibliográfica, revisões, monografias, teses, dissertações. Resultados: após a busca inicial, foram encontrados com os descritores sugeridos pelo DeCS zero estudos na BVS e 15 na PubMed. A partir de uma análise preliminar observou-se que nenhum dos artigos aborda exclusivamente a precificação de dispositivos médicos. Foram testados diversos descritores relacionados ao tema, mas sem sucesso nas bases definida. Apenas em uma pesquisa pela literatura cinzenta, três documentos nacionais foram encontrados que aborda exclusivamente o tema, estes não foram indexados em nenhuma revista até a presente data. Considerações finais: a partir dos dados, pôde-se observar que relativamente o tema é muito novo no Brasil e pouco abordado; a literatura internacional apresenta maior diversidade. Será necessário refazer a pesquisa utilizando o banco de dados Scopus e buscar com o padrão de descritores internacional, sendo estes: "Dispositivos Médicos" ou "Medical Device", termo utilizado mundialmente, sinônimo "Equipamentos e Provisões" (DeCS). Outro descritor é o de preços, sinônimo "Comércio" (DeCS), também não sendo retratado nos artigos, sendo indexados como "Price Transparency" ou "Price" e "Medical Devices Legislation".

Descritores: Equipamentos e Provisões; Legislação de Dispositivos Médicos; Comércio. 